\title{
Further Connections
}

Our previous chapters have drawn numerous connections between psychology and philosophy. They have in a variety of ways made use of psychological ideas to illuminate (I hope) a number of important philosophical issues or questions. In this chapter I would like to draw out some further implications of what was said in previous chapters. I will refer to particular chapters and in the case of each chapter I refer to I will attempt to make further connections between philosophy and psychology based on what the given chapter has already said on that topic. The further connections will in many cases, however, be far from obvious, and that is the main reason, apart from the value of the connections in intellectual terms, for being specific and explicit here about those further connections. I will start with Chap. 2 and then move on to later chapters.

\section{1}

In this first section I want to talk about some further implications of Chap. 2 and then go on to connect those implications with further implications that derive from our previous chapter (Chap. 7). Chapter 2 focused on human psychology and argued that the Chinese ideas of yin and yang, interpreted in one way that these ideas of been understood within Chinese tradition, can help us understand not only why that psychology is based in a heart-mind or xin rather than in what Westerners call the or a mind, but

M. Slote, Between Psychology and Philosophy, Palgrave Studies in Comparative East-West Philosophy, https://doi.org/10.1007/978-3-030-22503-2_8 
also help us to explain how sentimental virtues like compassion and benevolence work as moral virtues. Compassion, as we saw, has yin and yang aspects, and the way these necessarily work together constitutes the virtuousness or moral goodness of compassion.

I would like here to say more about the yin-yang implications of what was said in Chap. 2, but before I do that, I would like to draw some links between what Chap. 2 said about the heart-mind and larger issues of ethics that take us beyond individual moral sentiments like compassion and benevolence. The argument against mind and in favor of heart-mind was based on an attempt to show that emotion is necessarily involved in all psychological functioning; and Chap. 2 pointed out that this conclusion, if plausible, undercuts the whole idea of pure reason. And it is not just Kant but contemporary analytic philosophers too who believe that reason in the form of rational belief and rational action doesn't require emotion. All this, I have argued, is a huge mistake, one that has skewed or biased Western thought in a way that hasn't been true of Chinese philosophy. But the implications of what was said in Chap. 2 for ethics as a whole were not fully drawn out or even described in Chap. 2, and I want to do some of that now.

If there is no such thing as pure reason, if all rationality involves emotion, then ethical rationalism in particular is not, or is no longer, a viable project. We are left with some form of sentimentalism as the only game in town, and this will or would be a surprising conclusion not just for ethical rationalists in the analytic tradition (people like Thomas Nagel, Derek Parfit, and T. M. Scanlon), but also for analytic philosophers generally. I remember how startled and derisive a job candidate at the University of Maryland once was when, in answering his query as to my own interests as an ethicist, I told him I was interested in justice and emotion. That was certainly not a tactful reaction for someone to manifest toward what someone interviewing him for a job (I was in fact the department chair) was telling him, but it indicated a deep truth. The idea of a deep connection between justice and emotion has seemed or would seem too strange and even wild to analytic philosophers, but what was said in Chap. 2 of this book might hopefully and eventually counter such a reaction. Among analytic philosophers justice is itself typically regarded as having a rational basis, so if it turns out that reason is based in emotion, the idea that justice in society is a matter of emotion or emotional dispositions between and among the different members of a society will no longer be or seem be far-fetched. Emotion grounds and pervades not only individual moral sentiments like 
benevolence, but also larger-scale ethical issues including, most notably, questions about social justice. I have spelled out a sentimentalist theory of justice and of other central moral concepts in my book Moral Sentimentalism (OUP, 2010), and Appendix B will have a good deal to tell us in particular about sentimentally understood social justice and human rights. But for the moment suffice it to say that our present Chap. 2 all on its own tells us why emotion has to be regarded as basic within the entire sphere of ethics. ${ }^{1}$

Chapter 2, of course, also made great use of yin and yang to understand certain important aspects of what we are now calling the heart-mind, or xin. But I would like now to show you how yin and yang can help us understand human psychology or xin in a more general or overall way. Yin and yang illustrate or illuminate the emotion character of all psychological functioning or functionality, and Chap. 2 made this point very explicitly. But yin and yang can tell us more than Chap. 2 told us about what a xin necessarily is. Chapter 2 made much of the (argued for) fact that belief and desire are the basic (emotional) building blocks of our functioning xin, and it sought to show that both belief and desire can be analyzed in yinyang terms. But I believe we are also in a position to make a further and stronger claim about yin and yang in relation to xin. I think we can say that belief is the yin and desire is the yang of the heart-mind or xin. How can

\footnotetext{
${ }^{1}$ It is worth noting the difference between what Moral Sentimentalism (MS) sought to accomplish and what Chap. 2 of the present book enables us to do. The former develops and defends a sentimentalist moral view that it claims is superior to any form of ethical rationalism, but it doesn't seek to refute rationalism directly or outright. The idea rather is that sentimentalism in a certain new incarnation is superior to ethical rationalism and offers us reason to reject rationalism on that basis. Chapter 2 of the present book, by contrast, offers a direct refutation of ethical rationalism. What follows, as I have said above, is that some form of sentimentalism (perhaps one at certain points appealing to practical reason(s) but recognizing that every form of reason is based on emotional elements) has to be the right way to understanding ethics. But no particular version of sentimentalism follows out of the present Chap. 2, so its discussion needs to be supplemented in a large way by a book like MS if one is to argue for the form of sentimentalism I favor, one based in empathy (as Hutcheson's and Mengzi's sentimentalisms are not) and ultimately leading toward a yin-yang basis for all morality. (Yes, even for social justice, but then it has to be shown how the unfamiliar idea of empathic caring demonstrated at the social/political/legal level can be modeled on the more familiar idea of individual empathic caring. Much of this occurs in Chap. 9 of MS, but for a somewhat fuller and updated discussion see the second appendix of this book.) Going further, Chap. 2 above then effectively shows us how the whole individual-social empathic value package can be grounded in yin and yang, and the conclusion of The Philosophy of Yin and rang explains how abstractly understood and updated yin and yang are appropriate for the grounding of human values.
} 
this be, though, if each of belief and desire (already) contains yin and yang elements in inextricable connection with each other?

Here we need to distinguish between belief and the concept of belief and between desire and the concept of desire. Beliefs and desires contain both yin and yang elements, but our concept of belief foregrounds the yin aspects of beliefs, and our concept of desire foregrounds the yang aspects of desires. For example, Chap. 2 argues that beliefs have to involve emotion and in particular involve a desire for (or favorable attitude toward) making use of the proposition believed for instrumental purposes as relevant desires arise or exist within one. To believe the cupboard is bare (in the eighteenth century) is to favor using the idea or proposition that it is bare in conjunction with any desire for food that may arise, thus leading one to go out in search of food if and when that desire arises. So belief involves desire and/or motivation, and we think of desire and motivation as yang and actively purposive; but when we invoke the concept of belief, when we speak of beliefs, we are mainly focusing on the receptive or yin side of beliefs, the side or aspect that takes in the world rather than acting on the world. Similarly, desires like thirst involve both a desire to drink and a sensitivity to a certain dehydrated and uncomfortable physical state of one's throat or body, but when we talk of thirst and think of it, as we often do, as a certain kind of desire to drink, the yang aspect of the desire is highlighted. We are thinking of it more as an active impulsion toward drinking and less as a mode of being receptive to the state of one's body. So the idea or concept of thirst as a desire to drink highlights or foregrounds the yang and purposively active side of that desire.

But if belief is the yin of xin and desire is the yang of xin and if belief and desire are the basic ingredients, so to speak, of a functioning xin, then we can also and most generally conclude that the functioning heart-mind is a yin-yang thing or entity. However, we are not yet finished with the yin-yang philosophical implications that arise out of the earlier discussions of this book. What was said in Chap. 7 about curiosity/inquisitiveness can help us to see the role yin-yang can play in understanding issues in epistemology.

Epistemology over the modern period in the West has flowed in two main streams: foundationalism and coherentism. Foundationalism as originating in Descartes maintains that our beliefs and our knowledge require firm epistemological foundations (in our immediate experience); and by contrast coherentism as originating mainly in Hegelian-type objective idealism tells us that foundations in the Cartesian sense are unnecessary to the 
epistemic/theoretical justification of beliefs or supposed items of knowledge: a belief is justified if it coheres with the rest of one's beliefs and even if one has not provided and does not possess anything like epistemological foundations or bases for its acceptance. More recently, a new school of epistemological thought has arisen (or revived, because Aristotle's approach to theoretical knowledge has been the prime inspiration for this new school). The new school is called virtue epistemology, and it claims, roughly, that our beliefs are rational and justified to the extent they manifest epistemic/ theoretical/cognitive virtues. Such virtues include open-mindedness, intellectual courage, carefulness in weighing evidence, and, one might add, intellectual curiosity - or just plain inquisitiveness. I want to show you or, more accurately, sketch for you a way in which the last of these epistemic virtues, inquisitiveness, can be seen to play a role in the rational/epistemic justification of many of our ordinary beliefs. We shall then see how this ties in with yin and yang. (What I shall be saying in summary is expounded at full length in Chap. 4 of my The Philosophy of Yin and Yang.)

Think about what is required in order for someone to have a justified specific belief about some object or event in the world. In order to know that the table in front of one is oblong, one has to pay attention-one can't just let impressions swim by in a "blooming, buzzing confusion." But as Chap. 7 sought to teach us, paying attention and focusing standardly express our curiosity to know about the world around us. So inquisitiveness and curiosity are part and parcel of the process whereby we come to learn about the world around us. In order to have justified beliefs about the world we need to have a certain amount of curiosity and our justification with regard to particular beliefs obviously requires particular instances or manifestations of such curiosity.

But curiosity is an active motive, and when one out of curiosity focuses on what is happening, for example, to one's left, the curiosity acts in a particular direction. This is obviously a yang characteristic within the mind or xin, an example of directed (subliminal or unself-conscious) purpose. So our curiosity can be considered a yang epistemic virtue because it is essential to and part of the process of justifying particular perceptual beliefs. Where, though, is the yin in all this? Well, if you think about it, it is already hiding in plain sight within the foregoing discussion. When one is curious about what is happening or exists to one's left and looks there, one may learn through one's sense perceptions and one's knowledge of the relevant concepts that there is an oblong table to one's left. One's learning this, one's coming to justifiably believe this, depends on curiosity 
as expressed in focusing and paying closer attention, but it also depends on one's taking in what one's senses, and especially one's sense of vision, tell one about the object to one's left, and such perceptual and doxastic (belief-involving) taking in is a form of receptivity. We have previously identified yin with receptivity, and the epistemological receptivity involved in believing on the basis of what one's senses seem to indicate, what one's senses, as we say, tell us, is an epistemological virtue.

That virtue was already to some extent in evidence in what Chap. 2 said about the role of empathy in compassion. The compassionate person empathizes with the pain distress, say, of another person, and that empathy, if you think about it, is a way of being cognitively in touch with what the other is feeling. So receptive yin empathy has a cognitive or epistemic role we are already aware of. But I am saying now that yin receptivity is also involved in ordinary perceptual knowledge of objects in the world around us. It plays a role in our cognitive acquaintance with what others are feeling but also in what we learn or are justified in believing about the non-human world around us. Remember too what Chap. 5 says about the way empathy helps us to know objects or things beyond the minds or heart-minds of those we empathize with: we can know that bears are dangerous via receptive yin empathizing with our parents' fear of bears. So yin receptivity has a major role to play in the justification of beliefs both about other people and about the physical world around one, and the yang of actively focusing or paying attention in a directed way has a similar role to play in helping us to attain rational or justified beliefs about the world.

Moreover, in the process of learning about oblong tables and the like, the yin perceptual receptivity and yang curiosity are inseparable. If one isn't curious to know about the world and/or some particular thing in the world, then one isn't receptive to those things, and by the same token if one isn't cognitively yin receptive one isn't going to yang pay any real attention to anything. I could say more, but at this point I think it would be more interesting if we spoke of some of the other implications of our previous discussion in regard to the usefulness of psychology to our doing of philosophy

\section{2}

Chapter 3 criticized the assumption, made both East and West, that people can be primarily responsible for making themselves morally virtuous or morally vicious. I argued that our moral character depends much more on what we learn or receive from others than on what we deliberately and 
effortfully do for or to ourselves. Empathy was brought in at various points to underscore this last point and/or to give instances where moral education can and does occur through the help or influence of others: modeling and inductive discipline were mentioned in this connection. But part or parts of moral development don't involve anything that would naturally be called moral education, and Chap. 3 didn't talk of these other ways that we can be empathically influenced toward being morally better people. In fact empathy plays a role in extra-educational or what we might better call pre-educational moral development, and let me begin by mentioning one important way that this can occur.

Sibling rivalry comes naturally to children, but some people and some thinkers disagree. They say that it is entirely natural for children to love their siblings and downplay any role that sibling rivalry plays in family life or the life of given individuals growing up in a family environment. But we know that siblings tend to love each other, and so sibling rivalry can't be the whole story of the relationships that exist among brothers and sisters. If we cannot otherwise explain how siblings come to love or already love one another, we may have to agree-and what a pleasure or relief it will be to be able to do so! - that siblings do instinctually come to love one another once they recognize and experience their (normal) relationship with their sibling or siblings. But I think we can in fact explain intersibling love and can do so in terms of empathy. Yes, sibling rivalry is a basic fact about family life: when a new baby is born, a previous only child will naturally resent all the attention they get, attention that presumably was previously heaped on themselves. Children want to be loved and the birth of a sibling can seem to threaten the quantity or quality of the love one has been receiving from parents. This occurs with first-born children when a second child is born, but, perhaps to a lesser extent because they are already used to having rivals, also occurs with children other than a firstborn when later siblings are born.

All right, then, so there is such a thing as sibling rivalry, but there is a force that works against the negative feelings such rivalry embodies or gives rise to, and that force is empathy and most particularly empathy with the love one's parents bear to one's (new) sibling or siblings. If a father, as per Chap. 2, can be empathically infected by his daughter's enthusiasm for stamp collecting, a child can be empathically infected by their parents' love for some new or not new sibling. In effect, as we say, they identify with their parents' point of view on or attitude toward the sibling and ipso facto therefore feel some degree of love toward that sibling. Such an account of 
the love of one's siblings makes sense and doesn't blink the fact of sibling rivalry the way accounts of sibling love that posit a fundamental instinct to love family members tend to do. And learning to love one's siblings in this way is arguably a form of moral development, even if it doesn't occur as part of any process that we would normally label moral education. But let us now consider how or whether any of this transposes to other sorts of morally desirable love within the family. Does it help us understand how a child loves or comes to love her or his mother?

I don't think so. Because there is no one more basic in most children's lives than their mother that can serve as the basis for an empathic transfer of love to the mother. This might work with a father, in which case we are saying that empathy with the mother's love of her spouse can yield love for the spouse in much the same way empathy with parental love for one's siblings can make one love the siblings. But love for the mother is plausibly seen as more primordial than that. In that case, once again, one might posit that love of one's mother comes instinctually to most children, but that assumption comes up hard against the fact that many children come to hate their parents. As we saw in Chap. 6, children who are abused by parental figures often come to resent and hate those figures and to displace that resentment and/or hatred later on onto people who resemble them. If there really is an instinct of loving one's parents or one's mother, one would expect it to be hardier than love of one's parents often is. (I realize that in saying this I am taking issue with traditional Chinese thinking about these matters: as with Mengzi's claim in the Mencius 7Al5 that all children naturally love and continue to love their parents.) Parental abuse and mistreatment often entail that the child doesn't love their parents, and I think we would do best if we can come up with an explanation of that fact that also explains how love of one's parents can develop in the first place. Such an explanation to be most plausible must explain how love of one's parents can develop and how, with certain modes of treatment, a child can fail to develop a love of their parents. And I think such an explanation will make crucial use of the concept or phenomenon of empathy.

In accordance with what Chap. 7 told us about the basic need for love, we can assume that children have a very deep and strong need or desire to be loved by their parents. If the child isn't born with a love for (those they learn are) their parents, then the parental thwarting of the child's need for love will make the child angry or resentful toward their parent, and this anger and resentment will presumably be all the stronger if the parents actively abuse the child sexually, physically, or emotionally (rather than just 
withholding love). Such resultant hatred will effectively block the path to loving one's parents, but when parents do show love toward their child (and do provide adequate material benefits to the child), empathy will help the child develop a love for their parents or their mother in particular. If the child empathically feels how much their mother, say, loves them, they will tend to reciprocate that love. But the tendency to reciprocate isn't a fact so much about empathy as about the tendency of the mind or xin to give back what it receives from outside.

If someone feels, empathically feels, that they are hated or viewed indifferently, they will tend in turn to feel hatred or at least indifference to those who have regarded them that way and have behaved toward them accordingly. Chapter 6 already makes this clear, but we can add that this reciprocity of feeling partly depends on empathy. Children empathically know when they are hated or viewed as objects of indifference; they can feel such attitudes as they come toward them from those around them. There is no reason to think things operate any differently when a child is the object of friendly or loving feelings/attitudes and relevant resultant actions. So the fact that a child is loved can explain, in terms of xin's tendency to operate in a reciprocal way, why the child loves back, why the child loves the mother or parents who love them. There is no need, therefore, to posit a basic instinct of loving one's parents in order to explain how and why children typically love their parents, and our same fundamental explanation also helps us understand how and why an abused child will typically return the negativity of attitude and action that they empathically feel in those around them-and thus fail to develop any love for those people, parents or otherwise. There is no reason, then, to posit a basic instinct of loving parents, but our ability to avoid doing so does depend on the assumption, which we have made much use of, that the mind or xin works in a reciprocal fashion. ${ }^{2}$ We see evidence of this all

\footnotetext{
${ }^{2}$ It would be a mistake at this point (or any other) to say that we can explain the love of one's mother on the basis of the sheer fact of instinctual human empathy. There is evidence, to be sure, that well-loved children will start having compassionate empathy for people suffering or in trouble around them from a very early age (some studies indicate that this can happen when or even before a child is two years old). But empathic concern for someone in trouble lies far short of loving them, so we cannot explain the love of one's mother as due to maturationally developing empathy's simply focusing on the person who is most around one. Given how badly some children react to not being loved, we also cannot say that the love of one's mother can be explained in terms of one's sheer need for her love. The explanation offered in the main text above seems the best way forward. Of course, that explanation takes
} 
around us but it would be nice if we could say more. The reciprocity is not a sheer function of empathy though empathy plays a role in its occurrence. Can anything more be said by way of helping us to understand this phenomenon?

In psychology there are terms "afferent" and "efferent" that refer, respectively, to what comes into the mind or xin and to what comes out of or leaves the mind or xin. Reciprocity as we have described it involves both efference and afference. The mother's love, say, comes into and is empathically registered in the child's xin or mind and the child then directs a similar love toward a mother outside his or her mind. In this case, there seems to be a similarity and almost an equality between what comes into the mind from a given source and what goes out of the mind in the direction of that original source. Does this remind you of anything?

Well, it reminds me of Newton's third law of motion, according to which for every action there is an equal and opposite reaction. That law is supposed to hold for physical bodies and events, but one might wonder whether something similar governs human or other beings' psychology. What happens with the return of parental love by the child and with the return of parental indifference or worse by the child would then seem a

maternal love as a given, and one can wonder whether we can simply say that maternal love is an instinct. We can't say that if an instinct has to manifest itself in every instance, since we know some women don't feel love for their children. But instincts can be interfered with or fail to develop as a result of other factors, and I see no reason to deny that there is such a thing as a maternal (perhaps there is even a paternal) instinct. Mother crocodiles are very protective of their babies and provide them with water during their first weeks of life. Human mothers are similarly protective of their offspring and are also, of course, concerned with feeding them. We know that chemical changes in the body of a pregnant woman prepare her for such a role and those changes may graft onto her empathically loving feelings about her own previous family as based, presumably, on the factors I described in the main text above. (This means that if she is a psychopath incapable of empathy, she may not be able to genuinely love her child.) Phylogenetic evolution based on survival value can make ontogenetic sense of there being a typically automatic development of maternal feeling once a woman has given birth or before. And let me finally just make two points. First, maternal love seems implicitly to involve maternal esteem: the loved child is ipso facto viewed as wonderful. So maternal or parental love can simultaneously fulfill a child's desire for parental love and their desire for parental esteem. Second, the fact that children need love so much would suggest that when they get what they need, it us understandable that they should then feel gratitude for what they have been given. I think we can say that when the child feels the mother's love and reciprocates, the love that ensues arguably also constitutes a kind of gratitude for what they have received from her. I have assumed as much in the main text, and all of this ties in quite well with what was said about gratitude vis-à-vis thanking in Chap. 5. 
kind of psychological instance of Newton's third law, with the outwarddirected reaction of the child constituting, in the first place, a reaction opposite to what come into their mind (or xin) from the parent and with the reaction also being equal to what caused it inasmuch as it strongly resembles what caused it: love in the one case and some negative attitude in the other. I am inclined to think that an analogue of Newton's third law governs the relation between afferent and efferent phenomena, with the example of love and negative attitudes representing just one instance of its psychological application or instantiation.

Let me suggest that a further possible instance is already right under our nose. We have seen that empathy takes in the distress of others in a way that necessitates motivation to help-yin receptivity in that way being bound to yang directed purpose. But the example of pain distress mentioned in Chap. 2 not only illustrates yin and yang, but also exemplifies something like the kind of afferent-efferent relationship we have seen illustrated with attitudes of love and hatred. What empathy takes in, in the case I described, is another person's distress at the pain in their arm, which is equivalent, as we argued, to that other person's desiring to get rid of or diminish that pain. Well, and as we also saw, the empathy yields a corresponding compassionate motive/desire in the empathizer to get rid of that pain. What is taken in by way of motivation yields an outgoing motivation that matches the motivation that was empathically taken in. This too, then, seems like an example of Newton's third law as applying to afferent-efferent psychological phenomena, but there is no time for me here to explore this possibility further or to extend its application to further instances. What I have just been saying helps make sense of what happens when love for parents either develops or fails to develop in children and it also seems to work for central cases of compassion.

Going further, we might also say that the efferent-afferent phenomena of reciprocity can be subsumed under yin and yang. We already saw this with compassion in Chap. 2, but it seems to me that something similar can be said, for example, about the "pure" reciprocity that occurs when a child gratefully returns the love that their mother, say, has shown toward them. For a child not to love back shows or would show them to be empathically insensitive to all that their mother is showing and doing for them, and would be an example, therefore, of the absence of yang motivation/emotion necessarily involving the absence of yin receptivity. But by the same token, the child can't yang feel loving gratitude toward their mother if they don't yin receptively feel love from their mother, so we seem to have 
another example here of yin and yang and in particular of yin and yang subsuming the psychological reciprocity we have been describing. ${ }^{3}$ More needs to be said, but it is time we moved on to some related further points.

We spoke in Chap. 6 of the tendency of hatred or anger to displace itself from its original and perhaps appropriate target to other targets that are far less appropriate: as when a man who is angry with his boss comes home and kicks the dog or yells at his spouse. The good side of this tendency would involve love for others tending to displace itself from its original target to or toward others who may resemble the original object of the love. Love of one's parents or one's siblings might have some tendency to displace itself onto children or people who are outside one's family, and the possibility of loving people outside one's family will presumably be empathically reinforced (via the force of reciprocity) if and when such people take a liking to oneself. There is a lot of love and friendly feeling around in our society, but also a lot of hatred, distaste, and resentment, and I think empathy together with Newton-like afferent-efferent reciprocity can explain a lot of this. ${ }^{4}$ If we think there is a moral obligation

${ }^{3}$ In Chap. 2 I spoke of two ways of thinking of yin and yang. One involves seeing them as mutually complementary and consistent, the other sees them as contraries and mutually opposed. I have chosen the former way of understanding yin-yang, but one might wonder whether this is compatible with invoking Newton's third law with regard to either physical or psychological phenomena. If one yang presses a rubber ball with one's fingers, the ball yin receives the pressure and yang presses back against the fingers, which in turn yin register or receive that back-pressure. The forces involved here move in opposite directions just as the third law says, but they are in no way mutually incompatible and rather exist in a certain kind of balance. The (aspect of the Chinese) tradition that sees yin and yang as contraries holds that they cannot fully exist at the same place and time-as when yin is viewed as softness, stillness, femaleness, acidity, or coldness and yang as hardness, activity, maleness, alkalinity, or warmth. But the opposite directionality of forces Newton speaks of involves forces that at one and the same time fully exist in a kind of balance, and this means that, understood in the yin-yang terms I have been employing, the yin of the ball's receiving pressure and the yang of its exerting pressure are fully realized at the same time and place. So although the forces we are speaking of work in opposite directions, their yin and yang are realized together at one and the same time and are as compatible as one could wish. The same points apply to yinyang psychological afference and efference.

${ }^{4}$ Our love of one person tends not only to spread toward resembling others, but also to spread over the entire world. We say that everybody loves a lover, and I think that is in great part because someone in love tends to act and feel lovingly or warmly toward people generally, toward, as we say, the whole world. But hatred also tends to spread this way, and with some serial killers we can with some good reason say that they hate the whole world. In the Chinese tradition there is a difference of opinion as to whether human beings are basically good: with Mengzi holding that they are, Xunzi holding they are basically bad, and Kongzi 
to care for or about others, such an obligation can be psychologically backed by the psychological tendencies we have described here and in earlier chapters, but that suggestion opens out onto wide topics and issues that are best left to another philosophical occasion. It is time for us here and now to consider what other chapters of this book can help us to see about the connection between psychological knowledge or speculation and important philosophical issues.

\section{3}

I am not going to speak here of the implications of Chap. 4 because what Chap. 4 says, rather briefly, about open-mindedness can and should be expanded in a very large way. I have devoted the first appendix of this book to what can be said beyond the limited discussion of Chap. 4 about the virtue of open-mindedness, and the reader will or can see that the great deal that can be said further about open-mindedness is both surprising and somewhat dispiriting. So instead of speaking here in this chapter about what I take to be the most important consequences of thinking further about issues raised (about open-mindedness) in Chap. 4, let me focus now on some implications of the discussion of Chap. 5.

Chapter 5 dealt with a lot of different topics relating to empathy: hence its title, "The Many Roles of Empathy." It devoted much of its time to speech act theory and how empathy can enrich our understanding of speech acts, and I want to begin now with some reviewing and then some

remaining neutral. Mengzi's view dominates within the subsequent Confucian tradition, and of course in the West there seems to be the opposite tendency, with religious Christianity holding that we are born sinful and Kant saying that human beings are basically infected with radical evil. (Judaism doesn't say this sort of thing, however.) I think that the fact that both hatred and love tend to spread or displace themselves is a reason not to say that human beings are basically good nor to say that they are basically evil. What confirms me in that Kongzian neutrality are two further psychological facts: on the positive side, the fact (as per footnote 2 ) that in the absence of any explicit moral teaching, even very young children are capable of empathic concern for people in trouble around them, but, on the negative side, the fact that young children are so self-centered that they can hurt another child but pay no attention to the pain they have caused unless an adult, using the method of inductive discipline described in Chap. 3, deliberately gets them to focus what they caused to happen. Notice too that Kongzian neutrality fits in quite well with the overall characterization or picture of human life briefly described in footnote 3 of Chap. 7. Both the morally negative motive of displaced vengefulness and positive motives like empathic concern illustrate the basic human tendency to take things or people outside themselves into their lives. 
further implications of what was said there about speech acts. But Chap. 5 also had a number of things to say about moral concepts and moral knowledge as based in empathy, and after we say more about speech acts, I want to consider some further implications of Chap. 5 for our understanding of moral-psychological phenomena.

Chapter 5 pointed to a role empathy typically plays in getting the hearer of an assertion to share the confidence of the asserter in some proposition or idea they have asserted. It also talks about the fact that the asserter wants the hearer to share their confidence. But the main focus was on the way the hearer empathically takes in epistemic confidence rather than on the way, as it seems plausible to assume, that a hearer will also empathically take in the asserter's desire that the hearer become confident in what they are asserting. When someone asserts something to someone, they typically or frequently are assuring the person who hears them of what they are asserting, and the term "assure" already implies that they seek to convey (in both senses) confidence. But the hearer knows that asserting is a way of assuring hearers of something, that asserters want hearers to share their confidence, and when someone hear an assertion they naturally take in that desire in an empathic way. So then consider what happens when assertion has been successful from the standpoint of the asserter. The asserter will have empathically imparted their confidence to the hearer and that is what they wanted to do in making the assertion they made, but won't they also want to know whether their speech act has been successful in that way? Usually we assure someone of something because we want or need them to be confident of it for some purpose of our own, and the asserter will therefore to some degree be left on practical tenterhooks even if he has made the hearer confident, if he cannot determine whether he or she has succeeded in doing so.

However, it is often possible to see whether someone is or has been made confident of some fact, and sometimes, perhaps even often, such knowledge is conveyed via empathy. If empathy can tell us that someone wants our help or that, in negative cases, someone is unwilling to offer us any help, it can also tell us whether someone is confident about some matter, and this will be true in the case where someone has tried to make someone confident in the truth of some proposition but also, and more generally, about people's confidence in matters or issues we have not tried to influence them on. Imagine, then, that I have made you confident via your empathy with my confidence and am interested to see whether my attempt to make you confident, my assurance as to some matter, has been successful. Won't a speech act of assertion seem less than fully successful to 
an asserter if they empathically register a lack of consequent confidence on the part of the hearer, and won't it seem more of a success, both to the asserter but also from the standpoint of someone evaluating the success of a given speech act in a more impartial way, if the asserter is able to empathically pick up or otherwise learn that the hearer has come to share their confidence or even their certitude about the proposition that they have asserted? And won't the empathy with the hearer in the most favorable instances make the original asserter be confident that their addressee has become confident. Indeed, because the hearer typically knows that the asserter wants to impart their confidence, the cooperative hearer may deliberately give the asserter some sign that they are now confident about what has been asserted. But this may not be necessary if the asserter can empathically recognize (and the hearer knows that they can recognize) that the hearer is now confident about what has been asserted.

All of this means that in the most felicitous instances of the speech act of assertion confidence doubles back toward and into the asserter. As Jane Statlander-Slote has pointed out to me, this can more accurately or fully be put as showing that in fully successful assertions the first-order confidence in some proposition spreads empathically to a hearer whose firstorder confidence in what has been asserted then doubles back toward and to the asserter in the form of second-order confidence, confidence that the hearer addressee has acquired first-order confidence in what one has asserted. We can also say that in such cases there is a bidirectional empathic resonance between speaker and addressee, and I believe that we could show that similar resonances can occur with other speech acts and that they bind people together in socially significant ways.

However, before discussing the resonances that occur with other speech acts, let me first point to the implications of what we have just been saying about and with the notion of assuring. The fact that we in ordinary speech and in many or most contexts equate asserting with assuring indicates how widely it is believed that successful assertion conveys more than belief to the hearer or addressee. It also indicates, though more implicitly, our common belief that there is nothing linguistically or epistemically improper in this happening. But for this not to be improper, empathy must be able to justify and convey knowledge or justification about the world (and not just about people's psychological states) independently of rational inferences; and although we already drew that conclusion in Chap. 5, I hope it is reinforced by what I have been saying here about the way we ordinarily think and talk about assuring and assurance. 
We have also just seen that empathy, which we already know can lead toward socially useful compassion and benevolence, helps cement social relationships via its connection with the speech act of assertion. Let us now see how that might work with other speech acts. (In what follows I shall both recapitulate and extend things I said in Chap. 5.)

In the case of thanking, for example, the person who thanks has registered the good will or good intentions of the other and offers thanks that gratefully express good will and good intentions toward the person who has done the favor. But then the person who is thanked will in the most felicitous cases thank the thanker in that minimal but significant way in which saying "you're welcome!" expresses minor gratitude, gratitude for the fact that the other person is grateful. There is a lot of mirroring going on in such cases, probably more than what occurs in the most felicitous cases of assertion. But the reciprocity of good intentions that successful thanking involves and the reciprocity of feelings of confidence that occurs in the most felicitous ordinary cases of assertion both seem capable of building a (small) sense of community or caring between a speaker and a hearer or addressee, and if (as I suggested or hinted at above) there are moral imperatives regarding the creation and maintenance of a sense of community among interacting individuals, then ordinary speech acts can play a moral role that we have for the most part been unaware of. It is often said that there is a moral imperative to be honest in what one says to others, but this doesn't tell us how moral community can be strengthened or how speech acts can further the moral goals of community. This is a dimension of speech acts that has not, to my knowledge, been previously explored, but because I think satisfying further exploration of this topic would probably require a very lengthy discussion, even an entire book, I shall drop this topic and move on now to some other implications of what was said in Chap. 5.

Chapter 5 spoke of the moral and metaethical importance of empathy from the sentimentalist point of view, and since Chap. 2 tells us that there cannot be such a thing as pure reason, moral sentimentalism is starting to seem more and more like the only game in town. In Chap. 5 I was fairly brief in discussing the metaethics of a present-day moral sentimentalism (my own version) that emphasizes empathy. Empathy with others that leads one to help them is first-order empathy, empathy with the suffering or distress of others, but there is also such a thing as second-order empathy, empathy with someone's empathy or lack of empathy, and in Chap. 5 I mentioned that my metaethical account of the meaning of moral terms, 
as most completely spelled out in my book Moral Sentimentalism (MS), relies on (the concept of) second-order empathy. Chapter 5 sketched how being warmed by some agent's warmth toward some third party constitutes a kind of approval or ur-approval of that agent or her actions/attitude toward the third party and indicated that a feeling of chill at someone's unempathic attitude or actions constitutes disapproval or ur-disapproval of them. I then explained briefly that my semantic account of terms like "morally wrong" and "morally good" was based on this second-order kind of empathy. ${ }^{5}$ But now and in the spirit of reviving at least briefly the

${ }^{5}$ When a child empathically takes in the empathy their parent has toward one of their sib
lings, this is empathy psychologically based on or in (another person's) empathy, but it is not the second-order empathy with empathy that my sentimentalist metaethics equates with (a primitive form of) approval and uses as the reference-fixing basis of our moral concepts/ language. With second-order empathy so called, the object or focus of one's empathy is the other person's warmth or empathy toward some third party. But when one takes in one's parents' love, say, of one's little sister, one takes in their love (or altruistic concern) for that sister in a way that ensures one will love (be altruistically concerned about) her too. The little sister in that case has become the object or focus of one's empathic concern. By contrast, when one is warmed by someone's warmth toward a third party, one doesn't have to acquire that person's concern for or focus on the third party. One feels their warmth toward the third party without necessarily sharing their warm feelings toward the third party. In other words, the second-order empathy with empathy that I say constitutes ur-approval picks up on the empathic warmth of some agent without one's having to acquire any focus on the object of that agent's warm concern, without oneself being or having to be concerned about the welfare of that third party. It is like what is called pure contagion, as for example when one is in an angry crowd and picks up or is infected by the angry mood without knowing at all what the crowd is angry about. There is an important distinction that needs be made between empathy that is warmly concerned with the welfare of some person and empathy that contagiously registers just the warmth that an agent feels toward some third party and that doesn't necessarily/immediately involve any warm concern for the third party's welfare. It might seem ironic that it should be the latter kind of second-order and welfare-unconcerned empathy that on my view provides the reference-fixing basis for a concept of moral goodness that characterizes some agent only if they have warm concern for (the welfare of) others. That implication of my view might initially strike some readers as odd or problematic, but in that case they should consider the possibility that one cannot be contagiously warmed by someone's warmth toward a third party unless one is capable of empathy more generally or more basically. Yes, a child Claudia who sees her parent help some lame child might be empathically warmed by her parent's actions, and this might, I am arguing, be independent of Claudia's having any immediate concern for the other child and also, in fact, of Claudia's applying any explicit moral concepts in the given situation. But even so, this kind of empathy would be impossible if the child Claudia were incapable of herself feeling empathy for the suffering of others. To be warmed by what one's parent does one has to understand what one's parent is trying/wanting to do, but one cannot understand that unless one has some kind of idea of 
spirit of East-West philosophical interaction that animates the early chapters of this book, let me mention an interesting difference between Chinese philosophy and Western philosophy.

Western ethical theory has been dominated by ethical rationalism, but Chinese philosophy never has been, and there are in fact no ethical rationalists in the Western sense anywhere in the history of Chinese thought. Chinese thought has tilted more toward sentimentalism, but in the light of that fact it will be surprising for some of you to hear that Chinese philosophy nowhere talks of feeling warmed by the warm-heartedness of other agents or of being chilled by the cold-heartedness of others. By contrast, at least Hume in the Treatise speaks of how we can be warmed by the warmth a friend who helps his friend displays in doing so, and that can make one wonder whether the total absence of such talk within the main texts of Chinese philosophy indicates that the Chinese have different moral concepts from ours. If my account of such concepts in terms of second-order empathic warmth and chill is accurate to Western thinking

what it is to be motivated the way one's parent is, and someone incapable of empathizing with another person's suffering, someone who never has experienced that kind of empathy, will not understand what their empathic parent is trying to do. First-order empathy is therefore ontogenetically presupposed by the second-order kind that fixes the reference of moral terms even if it doesn't have to occur when that second-order kind occurs. And I want to claim that this is, via the argument just given, a conceptual truth. (On this view a psychopath doesn't understand what empathic caring is - since they have presumably never experienced it.) So on the theory I am proposing there is a necessary connection between approval as a secondorder phenomenon and first-order concern for others, and even if the connection is one of necessary (unidirectional) presupposition rather than a matter of necessary simultaneous coinstantiation, that sort of connection seems strong enough and deep enough to allow second-order empathy to play a role in our semantic understanding of concepts or terms like "morally good" that are instantiated only on the basis of someone's possessing first-order empathy. Incidentally, too, this theory of how approval occurs can be further supported by considering how naturally we tend to see the standpoint of a moral judge or (dis)approver as very different from the standpoint of the moral agent. That distinction can be explained if the approver of helping a third party doesn't have to be involved, as an agent, in wanting to help the third party. So the idea that in moral approval we are warmed by someone's beneficent actions toward some third party without having to be simultaneously interested in similarly benefiting that third party helps make sense of the common and intuitive philosophical distinction between the third-person standpoint of the moral judge and the first-person standpoint of the moral agent. What might at first seem implausible about the overall view I have defended ends up contributing to its moral-theoretical strength. For more on these distinctions, see my reply to Antti Kauppinen in Philosophia 45, 2017. (I am indebted here to discussion with Zhang Yan, whose queries made me clarify some distinctions I was already implicitly making.) 
and if the Chinese never think in such terms, we might well wonder whether the Chinese terms for what we take to be moral concepts actually convey concepts quite different from our own.

However, this worry can be short-lived if and once one realizes that ordinary Chinese people frequently and comfortably speak of being chilled by someone's attitude toward some third party. And also of warmth in both its first-order and second-order incarnations. We must remember too that Western philosophers in their rationalism rarely if ever bring in warmth or coldness. (Even Hume, who speaks of warmth at warmth never invokes the parallel idea of chill at cold-heartedness.) But if ordinary folk are comfortable with such language and concepts, that may just show that in their eagerness to insist on the importance or prerogatives of reason, Western ethicists have simply ignored what is staring them or ordinary folk right in the face. So what was said in MS about the semantics of moral language may hold water even if Western rationalists don't or wouldn't agree with sentimentalist moral semantics and even if the Chinese, who have never really engaged in metaethics, don't mention the phenomena of chill and warmth in their philosophical works.

\section{4}

I have spoken of moral development in the present chapter and in various other chapters of this book (most notably Chaps. 3, 6, and 7). But moral development is part of overall human development, and I will like to conclude this chapter and this book by saying something about this larger issue. Philosophers usually don't occupy themselves with the idea of human development, but my book Human Development and Human Life (HDHL) does take up that issue and does so in a rather systematic way, and what I said there illustrates and I hope illuminates the possibilities of fruitful interaction between psychology and philosophy in a way that immediately bears on the principal topic of the present book. It seems fitting as a capstone, therefore, to a book like the present one to bring in, if only briefly, some of the ideas of HDHL as they illustrate how philosophy and psychology can work fruitfully work together.

The most influential work on human development has been done by Erik Erikson in Childhood and Society (Norton, 1950, 2nd edition, 1963) and a number of other books. Erikson spoke of a human life cycle divided into stages, with each stage representing a challenge of or to human development. The earliest stage, which is supposed to set the stage for all the 
others, involves the issue of whether the child or baby is going to develop trust in the world around them. Later stages include issues about toilet training, about successfully navigating school life, and, most importantly as far as Erikson was concerned, about the kind of identity one will forge or attain as an adult. The attaining of an adult identify is often fraught with challenges and difficulties, and in that connection Erikson coined the now familiar term "identity crisis." But Erikson conceived adult identity in a very particular way, and here a bit of philosophy needs to come in as relevant to Erikson's views about what it is to have an identity.

Erikson originally spoke only of male identity and identity crises, and he treated identity formation as a precursor to developing long-term relationships with the other sex. He didn't really talk about homosexuality or transgenderism, and the long-term relationships he envisaged as occurring after identity is fixed or achieved were implicitly viewed as relationships with females. When people objected that he hadn't said anything about female identity formation, Erikson responded by claiming that female identity is different from male identity. Male identity is formed before a long-term or lifetime relationship with a female is entered into; female identity, by contrast, is formed by entering a long-term or lifetime relationship with a male.

Well, feminists were quick or fairly quick to respond to what they considered the sexism of this view of human development. Erikson treated women as lacking any capacity or need to have a career independently of their marriage, whereas such independence was assumed to be essential to acceptable or desirable male development. If it is morally wrong or unjust to deny women careers, then Erikson's view simply goes along with that injustice and can be faulted for having a psychologically distorted picture of women's capacities and aspirations, a picture distorted through the presence of objectionably sexist ethical views in Erikson's thinking about human development, human identity formation, and the human life cycle. We cannot perhaps totally evade the making of ethical commitments when we seek to offer a meaningful picture of the human life cycle and of human development. The word "cycle" and the word "development" both at least implicitly involve ideas of what is better and worse: it is better to develop than to fail to develop and the idea of a life cycle assumes that in later stages of a human life development ceases and there is a kind of regression to earlier development stages, as with the idea of a second childhood. 
As a student of Erikson's thought I have long sought a way to reconcile his insightful notions of a life cycle and of an adult identity (though he rarely if ever uses the qualifier "adult") with feminist values, and the second chapter of my book HDHL sought to do precisely that. What I argued there was that both career and family relationships are or can be fundamental concerns for both men and women. One's adult identity then is the (possibly revisable) choice a man or woman eventually makes as to how much to emphasize career self-fulfillment and how to emphasis family or, more generally, close relationships in one's ongoing adult life. Some identities will emphasize one of these goals or interests more than or even to the exclusion of the other, but there is no sexism if one is allowing a male identity to involve being a stay-at-home husband and a female identity to involve a total involvement with career at the expense of longterm intimate or personal relationships.

In this case considerations of ethics and of feminist philosophy in particular interact or intersect with psychological considerations concerning human growth and development to allow us to theorize a conception of adult identity and of childhood development toward such an identity that cannot be accused of sexism and that seems at the same time psychologically realistic. The picture arrived at did leave out any account of identity and development as relevant to LGTBQ concerns, but I believe its rejection of sexism offers a clear blueprint for those who might want to talk about adult identity, human development, and the human life cycle in a way that takes in these other important life options. All in all, then, HDHL illustrates the possibilities of fruitful interaction between philosophy and psychology in way that the present book in a much larger way does too.

Finally, and with relevance to the three lectures at Nankai University that form the original basis for this book and that can be found in expanded form in the three chapters that follow the introduction here, let me mention an important connection between what we have just been saying about adult identities and yin-yang. In Chap. 2 we saw how yin-yang might help us understand the foundations of moral virtue, but I think what we have just been saying about adult identity can also receive yinyang backing. A career-based identity can only succeed if the person is not only directedly active within their field but also open and receptive to the traditions of that field and to the ideas of their contemporaries: this is clearly an instance of yin-yang (and it is far from excluding creativity). Similarly, a stay-at-home father or mother can do well in their choice of adult identity only if they are both receptive to the needs of their children 
and their household and also active in response to those needs. Again, a matter of yin-yang. I have written at some length about the connection between yin-yang and adult identities in Chap. 1 of The Philosophy of Yin and Yang, but it seems appropriate to conclude this chapter on the present note because it so clearly brings together the overall title theme of this book, the usefulness of psychology to philosophy, with the East-West theme of the three Nankai University lectures that were the propagating seed for the present volume. (For more on yin-yang ethics in relation to developmental psychology, see Appendix C of this book. There I speak about the connection between yin-yang adult identity and the having of a good life in a way that goes beyond anything in my previous work.)

Open Access This chapter is licensed under the terms of the Creative Commons Attribution 4.0 International License (http://creativecommons.org/licenses/ by $/ 4.0 /$ ), which permits use, sharing, adaptation, distribution and reproduction in any medium or format, as long as you give appropriate credit to the original author(s) and the source, provide a link to the Creative Commons licence and indicate if changes were made.

The images or other third party material in this chapter are included in the chapter's Creative Commons licence, unless indicated otherwise in a credit line to the material. If material is not included in the chapter's Creative Commons licence and your intended use is not permitted by statutory regulation or exceeds the permitted use, you will need to obtain permission directly from the copyright holder.

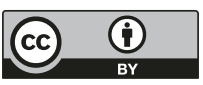

